\title{
Improving Disaster Data Systems to Inform Disaster Risk Reduction and Resilience Building in Australia: A Comparison of Databases
}

\author{
Joseph Cuthbertson, MPH, MSC, MEH; ${ }^{1}$ (i) Frank Archer, MD, PhD; ${ }^{1}$ Andy Robertson, MD, CSC, \\ PSM; ${ }^{2}$ Jose M. Rodriguez-Llanes, DrPH ${ }^{3}$
}

1. Monash University Disaster Resilience Initiative, Melbourne, Victoria, Australia

2. Western Australia Department of Health, Perth, Western Australia

3. European Commission, Joint Research Centre, Ispra, Italy

Correspondence:

Dr. Jose M. Rodriguez-Llanes

European Commission Joint Research Centre Directorate of Sustainable Resources

D5 Via Fermi 2749, TP272 21027 Ispra (VA), Italy

E-mail: jose-manuel.rodriguez-1lanes@ ec.europa.eu

Conflicts of interest/funding: none

Keywords: disaster; disaster data; disaster

database; disaster measurement; risk reduction

Abbreviations:

AIDRKH: Australian Institute Disaster Resilience Knowledge Hub

CE-DAT: Complex Emergencies Events Database CRED: Centre for Research on the Epidemiology of Disasters

DRR: Disaster Risk Reduction

EM-DAT: Emergency Events Database

UN: United Nations

UNDP: United Nations Development Program

Received: December 16, 2020

Revised: March 3, 2021

Accepted: May 16, 2021

\begin{abstract}
Objective: Disaster impact databases are important resources for informing research, policy, and decision making. Therefore, understanding the underpinning methodology of data collection used by the databases, how they differ, and quality indicators of the data recorded is essential in ensuring that their use as reference points is valid.

Methods: The Australian Disaster Resilience Knowledge Hub (AIDRKH) is an opensource platform supported by government to inform disaster management practice. A comparative descriptive review of the Disaster Mapper (hosted at AIDRKH) and the international Emergency Events Database (EM-DAT) was undertaken to identify differences in how Australian disasters are captured and measured.

Results: The results show substantial variation in identification and classification of disasters across hazard impacts and hazard types and a lack of data structure for the systematic reporting of contextual and impact variables.

Conclusions: These differences may have implications for reporting, academic analysis, and thus knowledge management informing disaster prevention and response policy or plans. Consistency in reporting methods based on international classification standards is recommended to improve the validity and usefulness of this Australian database.
\end{abstract}

Cuthbertson J, Archer F, Robertson A, Rodriguez-Llanes JM. Improving disaster data systems to inform disaster risk reduction and resilience building in Australia: a comparison of databases. Prehosp Disaster Med. 2021;36(5):511-518.

\section{Introduction}

The frequency and severity of natural disasters is increasing, the effects of which are spread over greater geographical and increasingly populated areas. In the Australian context, the increasing risk to the built and natural environments related to increasing frequency and intensity of extreme weather events is described by the National Strategy for Disaster Resilience. ${ }^{1}$ Such risks have been realized by vast bushfires which swept across multiple states causing widespread destruction on the east coast of Australia over the summer of 2019/2020. To empower principles of "building back better," resiliency, and supporting future disaster risk reduction (DRR) efforts and policy interventions in this context, an accurate understanding of hazards, threats, risks, and vulnerabilities is required. Measurement and understanding of the impacts caused by disaster informs policy makers and operational decision makers on investment strategies related to disaster. However, disaster risk analysis varies between institutions, partly due to differences in how disaster threats are defined and measured, and thus quantified. Previous studies in Australia measuring heatwave, a common Australian hazard, have demonstrated challenges in standardization of terminology and definitions, as well as data collection. ${ }^{2}$

The main weakness with disaster data is the lack of standardized methodologies and definitions for the inclusion of disasters $^{3}$ and robust impact measurement

doi:10.1017/S1049023X2100073X

(C) The Author(s), 2021. Published by Cambridge University Press on behalf of World Association for Disaster and Emergency Medicine. This is an Open Access article, distributed under the terms of the Creative Commons Attribution licence (http://creativecommons.org/licenses/by/ 4.0/), which permits unrestricted re-use, distribution, and reproduction in any medium, provided the original work is properly cited. 


\section{DISASTER MAPPER}

A disaster, as defined by the Australian Institute for Disaster Resilience, is a serious disruption to community life which threatens or causes death or injury in that community and/or damage to property which is beyond the day-to-day capacity of the prescribed statutory authorities and which requires special mobilization and organization of resources other than those normally available to those authorities. ${ }^{14}$

Box 1. Disaster Definitions in EM-DAT and Disaster Mapper

\section{EM-DAT}

EM-DAT defines a disaster as: "A situation or event which overwhelms local capacity, necessitating a request to a national or international level for external assistance; an unforeseen and often sudden event that causes great damage, destruction, and human suffering."15 methodologies. ${ }^{4}$ Accurate accounting for disaster impacts is a critical aspect of improving disaster risk management, DRR, and resilience building. ${ }^{5}$ Historical data are commonly used by analysts to track disaster trends and causal factors both over time and geographically. At subnational levels, disaster databases provide key information to signal hotspots of hazard or risk and design locally tailored actions plans or investigate regional trends. They can also be used to monitor progress in effectiveness of government strategies to reduce disaster impacts on population health and the economy.

Demand for clear, accurate, and consistent reporting of economic impact related to disaster in Australia is driven primarily from government and academia/research. Whilst a number of individual hazard-specific reports have been produced to date, the only comprehensive national impact assessment of economic loss related to disaster in Australia was conducted by The Bureau of Transport Economics (BITRE; Canberra, Australian Capital Territory) in $2001 .^{5}$

Other disaster databases include data from Australia such as DesInventar, ${ }^{6}$ Swiss RE: Sigma, ${ }^{7}$ and Munich RE: NatCat. ${ }^{8}$ In the Oceania region, reporting systems include the Australia Disaster Assist ${ }^{9}$ and the Insurance Council of Australia Catastrophe Database, ${ }^{10}$ which reports on insurance losses from 1967 to the present. At the time of writing, a new database has been developed using data from the Australian Institute for Disaster Resilience (Melbourne, Victoria, Australia) Knowledge Hub (AIDRKH) and is currently available on request. ${ }^{11}$

This paper provides a comparative, descriptive review of disaster hazards in Australia as measured by a domestic disaster database, The Disaster Mapper at AIDRKH, and an international one, the Emergency Events Database (EM-DAT), to gain new insights on its compatibility with international standards of disaster data classification, reporting, and access.

\section{Methods}

Studies comparing databases on disaster losses have broadly differed in their methodological approaches, ${ }^{3}$ ranging from narrative descriptions to mixed methods analyses ${ }^{12}$ and expert assessments or systematic reviews. ${ }^{13}$ Methodologies must be adapted to the purpose of the particular study and other constraints. This study used a combination of qualitative (eg, disaster definitions) and quantitative methods (eg, number of disaster events) to conduct the presented comparisons.

A comparative descriptive review of a national and an international disaster database was undertaken to examine differences in disaster definition and data entry thresholds, classification, impact (human, economic, and contextual), as well as accessibility and data structure. The choice of these variables was based on the review of past efforts to compare disaster databases. ${ }^{3,12,13}$ The databases used in the comparative review were the Australian Disaster Mapper based at the AIDRKH ${ }^{14}$ and the EM-DAT database of the Belgium-based Centre for Research on the Epidemiology of Disasters (CRED; Brussels, Belgium). ${ }^{15}$ These were purposively selected as the aim of the study was to provide a detailed account of whether the Disaster Mapper fulfills international standards for disaster databases according to a recognized and long-lasting initiative.

To conduct these comparisons, relevant information was scrutinized and extracted, including data, definitions, and classifications of the abovementioned variables from the corresponding sections of both websites. ${ }^{14,15}$ Relevant data on disasters and their impacts were downloaded to compare disaster frequencies for comparable categories of disasters, whenever possible.

The AIDRKH Disaster Mapper contains information on disasters affecting Australia and some international disasters that have impacted Australians since 1869. The Disaster Mapper was designed to support and inform policy, planning, decision making, and practice in disaster resilience and is managed by the Australian Institute for Disaster Resilience on behalf of the Australian Government. The Disaster Mapper includes natural, technologi$\mathrm{cal}$, and human-caused events that have a significant impact on Australia and its population. It is presented as an interactive visualization tool of disasters in Australia, supported by the annual Major Incident Reports involving Australian fire and emergency services. Disaster Mapper is likely the most comprehensive, publicly available national dataset, according to authors' knowledge.

In 1988, CRED created the EM-DAT with initial support from the World Health Organization (WHO; Geneva, Switzerland) and the Belgian Government. The EM-DAT houses international disaster impact data from 1900 to the present day. The objective of the database is to serve and support national and international decision making for disaster preparedness, vulnerability assessment, and prioritize resource allocation for disaster response. The EM-DAT is a world-recognized and internationally-standardized source for disaster data and widely used by the United Nations (UN), international organizations, politicians, and academia.

\section{Results}

\section{Disaster Definitions}

The United Nations Office for Disaster Risk Reduction (UNDRR; Geneva, Switzerland) defines a disaster as "a serious disruption to the functioning of a community, which causes human, material, economic, and environmental losses beyond a community's ability to cope."16 The definitions of disaster used by each of the investigated databases are shown in Box 1. The definitions of disaster in the Disaster Mapper and EM-DAT are, with their lexical differences, well-aligned. They provide a clear understanding that disaster is a situation exceeding or overwhelming available resources at a certain level of aggregation, social or geographical, causing personal and/or material damage, and requiring more resources than those available at the affected communities. 


\begin{tabular}{|c|c|c|}
\hline & Disaster Mapper & EM-DAT \\
\hline Disaster Entry Thresholds & $\begin{array}{l}\text { A disaster, as defined by Disaster Mapper, is } \\
\text { three or more deaths; or } 20 \text { injuries or illnesses; } \\
\text { or significant damage to property, infrastructure, } \\
\text { agriculture, or the environment; or disruption to } \\
\text { essential services, commerce, or industry at an } \\
\text { estimated total cost of } A \$ 10 \text { million or more at } \\
\text { the time the event occurred; and include event } \\
\text { occurring in Australia or directly impacting on } \\
\text { Australians. }{ }^{10}\end{array}$ & $\begin{array}{l}\text { A disaster, as defined by the EM-DAT database, } \\
\text { is ten or more people reported killed, or one } \\
\text { hundred or more people reported affected, or } \\
\text { declaration of a state of emergency or a call for } \\
\text { international assistance. }{ }^{11}\end{array}$ \\
\hline Reported Variables (Impact and Context) & $\begin{array}{l}\text { Disaster Mapper database entries include date } \\
\text { of event (Temporal Coverage } 1753-2014) \text {, } \\
\text { location (state and country), and disaster cat- } \\
\text { egory. Narrative text accessible per event } \\
\text { online contains additional information contex- } \\
\text { tual to the event. }\end{array}$ & $\begin{array}{l}\text { The EM-DAT database includes information on } \\
\text { the location (country or countries in which the } \\
\text { disaster has occurred), the exact date of the } \\
\text { disaster (start and end whenever possible), } \\
\text { disaster categories, number of deaths, number } \\
\text { of people injured, number of people homeless, } \\
\text { number of people affected, and estimated } \\
\text { economic damage. }{ }^{11}\end{array}$ \\
\hline
\end{tabular}

Table 1. Disaster Database Entry Thresholds and Summarized Recorded Variables

Cuthbertson @ 2021 Prehospital and Disaster Medicine Abbreviation: EM-DAT, Emergency Events Database.

\section{Disaster Database Entry Thresholds}

Disaster databases apply criteria related to their respective definition of disaster that prescribe which events do and do not get recorded. Table 1 shows the entry criteria used by the two examined databases in this research. The mortality entry threshold, one consistently used across databases, was lower in the Disaster Mapper compared to EM-DAT, which could yield an increased ability to report disasters in the former.

\section{Disaster Classifications}

The Hazard and Peril Glossary is used for describing and categorizing disasters in the EM-DAT database, shown in Table $2 .{ }^{17}$ The Disaster Mapper database does not contain specific disaster definitions, yet it includes 17 disaster categories, which at times were found to be different compared to those in EM-DAT. Table 2 presents the disaster categorizations in both databases, in which EM-DAT contains more sub-categories of disasters. A notable difference is the use of a category labelled "environment" (Disaster Mapper) to classify extreme temperature and droughts (EM-DAT).

\section{Impact Variables}

The National Disaster Resilience Strategy endorses the consideration of risk and risk treatment across social, built, economic, and natural environments of a community. ${ }^{1}$ The Australian Institute for Disaster Resilience describes these four as recovery impact environments in the National Disaster Risk Reduction Framework. ${ }^{18,19}$ When planning for community needs, this framework guides planners on the interdependency of the four environments in considering and coordinating interventions.

Event impact variables provided by the Disaster Mapper vary between event type; however, deaths and injured due to an event are commonly reported in narrative text related to the event when accessed individually online. Event impact data of both databases are shown in Table 3.

\section{Context Variables}

Raw data in EM-DAT database contain further, context-related information not visible via the online portal. These context variables are described in Table 4.

All events recorded in the Disaster Mapper can be individually viewed and contain a brief narrative of the event and its impact from where some contextual variables could be potentially obtained. Annual major incident reports have been produced by AIDKH for the last three years based on database inputs.

\section{Database Accessibility}

The EM-DAT database is accessed through an online portal requiring a username and password applied for through the CRED website. The EM-DAT database provides several standardized reports that can be generated and customized to region, country, and disaster. Advanced search functions on EM-DAT allow for specific event searches and automatic report generation, the data of which can be extracted. Access requires registration as a user.

Events recorded in the Disaster Mapper are publicly accessible and can be viewed as multiple or single disaster categories; however, event data can only be accessed per event and report or data extraction is not available through direct online access.

\section{Disaster Database Recorded Events}

All disaster data were manually extracted from the Disaster Mapper database. As of November 1, 2019, a total of 416 events had been entered: 396 of these were events that occurred in Australia and 20 events that affected Australian nationals abroad occurred internationally. Table 5 shows Disaster Mapper events by category type in order of number of events (top 10) built using all available data from 1869 to 2019. Table 6 is a direct extract of data from EM-DAT, which shows Australian disasters from 1900 to 2019 also in order of number of events (top 10).

Whilst the original start date of recording of data differs between the two databases (1869 versus1900), there were only seven (7) events recorded in the difference between these time periods: five (5) floods and two (2) industrial accidents. ${ }^{16}$ Inclusion of these events does not substantially alter the proportionate difference in numbers of events or make the databases more comparable. The observed trends in these comparisons were overall as expected. With increased sensitivity in Disaster Mapper, this database recorded increased number of floods and wildfires, with very substantial differences for epidemic outbreaks and industrial accidents. Storms and droughts presented more comparable numbers across databases, while other categories could not be assessed from Table 5 and Table 6. 


\begin{tabular}{|c|c|c|c|c|}
\hline \multicolumn{4}{|c|}{ CRED Emergency Events Database (EM-DAT) } & \multirow{2}{*}{\begin{tabular}{|c|} 
Disaster Mapper \\
Disaster Category
\end{tabular}} \\
\hline $\begin{array}{l}\text { Disaster } \\
\text { Group }\end{array}$ & $\begin{array}{l}\text { Disaster } \\
\text { Sub-Group }\end{array}$ & Definition & Disaster Main Type & \\
\hline \multirow[t]{13}{*}{ Natural } & \multirow[t]{3}{*}{ Geophysical } & \multirow{3}{*}{$\begin{array}{l}\text { A hazard originating from solid earth. This term is } \\
\text { used interchangeably with the term geological } \\
\text { hazard. }\end{array}$} & Earthquake & Earthquake \\
\hline & & & Mass Movement (dry) & Landslide \\
\hline & & & Volcanic Activity & \\
\hline & \multirow[t]{3}{*}{ Meteorological } & \multirow{3}{*}{$\begin{array}{l}\text { A hazard caused by short-lived, micro- to meso- } \\
\text { scale extreme weather and atmospheric condi- } \\
\text { tions that last from minutes to days. }\end{array}$} & Extreme Temperature & Environment \\
\hline & & & & Cyclone \\
\hline & & & & Tornado \\
\hline & \multirow[t]{2}{*}{ Hydrological } & \multirow{2}{*}{$\begin{array}{l}\text { A hazard caused by the occurrence, movement, } \\
\text { and distribution of surface and subsurface fresh- } \\
\text { water and saltwater. }\end{array}$} & Flood & Flood \\
\hline & & & Landslide & Landslide \\
\hline & \multirow[t]{3}{*}{ Biological } & \multirow{3}{*}{$\begin{array}{l}\text { A hazard caused by the exposure to living organ- } \\
\text { isms and their toxic substances (eg, venom, mold) } \\
\text { or vector-borne diseases that they may carry. } \\
\text { Examples are venomous wildlife and insects, poi- } \\
\text { sonous plants, and mosquitoes carrying disease- } \\
\text { causing agents such as parasites, bacteria, or } \\
\text { viruses (eg, malaria). }\end{array}$} & Epidemic & Health \\
\hline & & & Insect Infestation & \multirow[t]{2}{*}{ Biosecurity } \\
\hline & & & Animal Accident & \\
\hline & \multirow[t]{2}{*}{ Extra-Terrestrial } & \multirow[b]{2}{*}{$\begin{array}{l}\text { A hazard caused by asteroids, meteoroids, and } \\
\text { comets as they pass near-earth, enter the Earth's } \\
\text { atmosphere, and/or strike the Earth, and by } \\
\text { changes in interplanetary conditions that effect the } \\
\text { Earth's magnetosphere, ionosphere, and thermo- } \\
\text { sphere. }\end{array}$} & Impact & \\
\hline & & & Space Weather & \\
\hline \multirow{11}{*}{ Technological } & \multirow{3}{*}{ Industrial Accident } & & Radiation & \multirow{3}{*}{ Industrial } \\
\hline & & & Oil Spill & \\
\hline & & & Other & \\
\hline & \multirow[t]{4}{*}{ Transport Accident } & & Air & \multirow[t]{3}{*}{ Transport } \\
\hline & & & Road & \\
\hline & & & Rail & \\
\hline & & & Water & Maritime/Coastal \\
\hline & \multirow[t]{4}{*}{ Miscellaneous Accident } & & Collapse & \multirow{3}{*}{$\begin{array}{l}\text { Industrial } \\
\text { Fire - Urban }\end{array}$} \\
\hline & & & Explosion & \\
\hline & & & Fire & \\
\hline & & & Other & $\begin{array}{l}\text { Criminal } \\
\text { Other Disasters }\end{array}$ \\
\hline
\end{tabular}

Table 2. Comparison of Disaster Classifications in EM-DAT and Disaster Mapper Abbreviation: EM-DAT, Emergency Events Database.

Furthermore, the Disaster Mapper contains an "Other” category where two recorded events have been entered. Box 2 shows a summary of these events. In contrast, the EM-DAT database does not record war or conflict-related events.
The EM-DAT database does include a category of miscellaneous accident in the technological category, which also holds an "other" selection. Only one event in this category has been captured in the EM-DAT database relating to an event occurring in 1990 


\begin{tabular}{|c|c|c|c|}
\hline & \multirow{2}{*}{$\begin{array}{l}\text { Disaster Mapper Environments } \\
\text { Social Environment }\end{array}$} \\
\hline \multicolumn{3}{|c|}{ CRED Emergency Events Database (EM-DAT) Impact Data Categories } & \\
\hline & & Missing & \\
\hline & & Injured & \\
\hline & & Affected & \\
\hline & & Homeless & \\
\hline & \multirow{2}{*}{ Economic } & $\begin{array}{l}\text { Reconstruction Cost (in 000US\$ current } \\
\text { value) }\end{array}$ & \multirow{2}{*}{ Economic Environment } \\
\hline & & Insured Losses (in 000US\$ current value) & \\
\hline & \multirow[t]{3}{*}{ Disaster } & $\begin{array}{l}\text { Sectors Affected by the Disaster } \\
\text { (Animals, Industry, Electricity, Water } \\
\text { Supply/Sanitation, Communications, } \\
\text { Cultural Infrastructure, Transportation, } \\
\text { Other) }\end{array}$ & Built Environment \\
\hline & & Comments (all other relevant information) & \multirow[t]{2}{*}{ Natural Environment } \\
\hline & & Other & \\
\hline
\end{tabular}

Table 3. Disaster Impact Variables in EM-DAT and Disaster Mapper

Abbreviations: CRED, Centre for Research on the Epidemiology of Disasters; EM-DAT, Emergency Events Database.

\begin{tabular}{|c|c|}
\hline $\begin{array}{l}\text { Thematic } \\
\text { Classifications }\end{array}$ & Variables \\
\hline \multirow{6}{*}{$\begin{array}{l}\text { Geographical } \\
\text { Information }\end{array}$} & Country (if a disaster has affected more than one country, there will be one entry for each country) \\
\hline & ISO Code (International Organization for Standardization 3-letter code for each country) \\
\hline & Region (as per the UN regional division) \\
\hline & Continent \\
\hline & River Basin (if flood event) \\
\hline & Latitude/Longitude/Location (eg, name of a city, village, department, province, state, or district) \\
\hline \multirow[t]{3}{*}{ Temporal Information } & Start Day/Month/Year \\
\hline & End Day/Month/Year \\
\hline & Local Time \\
\hline \multirow{4}{*}{$\begin{array}{l}\text { Physical } \\
\text { Characteristics }\end{array}$} & Origin \\
\hline & Associated Disasters 1 and 2 (ie, landslide post-earthquake) \\
\hline & Disaster Magnitude Scale and Value \\
\hline & Other \\
\hline \multirow[t]{4}{*}{ Status } & Aid Contribution: Total Amount (given in 000US\$) \\
\hline & OFDA Response \\
\hline & Appeal for International Assistance and Date \\
\hline & Declaration of Disaster and Date \\
\hline
\end{tabular}

Table 4. Context Variables in EM-DAT

Cuthbertson ๑ 2021 Prehospital and Disaster Medicine

Abbreviations: EM-DAT, Emergency Events Database; UN, United Nations; OFDA, Office of US Foreign Disaster Assistance.

that resulted in 25 deaths. Following inquiry with the database management team, no detailed information was available to describe this event.

Other notable differences include the categories of "health" and "criminal" in the Knowledge Hub. Further investigation of the "health" category revealed details of events such as heatwaves, food poisoning, listeria, gastroenteritis, coral poisoning, poliomyelitis, bubonic plague, Spanish flu, and bird flu (H1N1) events. These events are captured and recorded in different categories listed in EM-DAT (ie, biological, meteorological). 


\begin{tabular}{|l|c|}
\hline $\begin{array}{l}\text { Australian Disaster Mapper } \\
\text { Categories }\end{array}$ & Number of Events 1869-2019 \\
\hline Flood & 80 \\
\hline Fire - Bushfire & 65 \\
\hline Industrial & 53 \\
\hline Cyclone & 45 \\
\hline Storm & 39 \\
\hline Health & 34 \\
\hline Fire - Urban & 20 \\
\hline Transport & 19 \\
\hline Environment & 14 \\
\hline Criminal & 7 \\
\hline
\end{tabular}

Cuthbertson @ 2021 Prehospital and Disaster Medicine

Table 5. Australian Disaster Mapper Disasters (Top 10 by Number of Events)

\begin{tabular}{|l|c|}
\hline EM-DAT Disaster Type & Number of Events 1900-2019 \\
\hline Storm & 107 \\
\hline Flood & 64 \\
\hline Wildfire & 41 \\
\hline Transport Accident & 23 \\
\hline Drought & 11 \\
\hline Miscellaneous Accident & 8 \\
\hline Extreme Temperature & 7 \\
\hline Earthquake & 4 \\
\hline Epidemic & 2 \\
\hline Industrial Accident & 2 \\
\hline Insect Infestation & 2 \\
\hline Landslide & 2 \\
\hline \multicolumn{2}{|c|}{ Cuthbertson $\odot 2021$ Prehospital and Disaster Medicine }
\end{tabular}

Table 6. EM-DAT Australian Disaster Events (Top 10 by Number of Events)

Abbreviation: EM-DAT, Emergency Events Database.

\begin{tabular}{|l|l|}
\hline August 5, 1944 & $\begin{array}{l}\text { A Prisoner of War (POW) } \\
\text { attempted mass escape in Cowra, } \\
\text { New South Wales resulted in 235 } \\
\text { deceased and 108 injured }\end{array}$ \\
\hline February 19,1942 & $\begin{array}{l}\text { Wartime bombing in Darwin, } \\
\text { Northern Territory resulted in 243 } \\
\text { deceased and 400 injured }\end{array}$ \\
\hline
\end{tabular}

Cuthbertson ๑ 2021 Prehospital and Disaster Medicine

Box 2. Australian Disaster Mapper Database "Other" Events

Investigation of the "criminal" category in the Knowledge Hub found ten (10) events, five (5) of which were terrorist events that occurred overseas. The EM-DAT database does not include terrorist attacks or other criminal-related events as a disaster category.

The Australian Institute for Disaster Resilience has published three (3) reports based on events recorded in the Knowledge Hub. Titled "Major Incidents of the Year," reports for 20162017, 2017-2018, and 2018-2019 have been produced. Each report provides an overview of major incidents that have involved the fire and emergency services sector during the corresponding financial year. The intent of the reports is to examine incidents identified by the sectors that were of significant impact or consequence for fire and emergency services. The reports are not a review of all incidents occurring during the period defined and are intended to provide key insights related to the events described. These publications provide a user-friendly resource for emergency service operators to engage with lessons learned in their field.

Currently, CRED provides a biannual newsletter based on EMDAT data, an Annual Disaster Statistical Report, and CRED Crunch, a newsletter published typically every three to six months. The newsletter focus is broad and reflective of international disasters. On occasion, EM-DAT data are used for international reports with a thematic focus.

\section{Discussion}

This study compared essential characteristics of the EM-DAT database and the Disaster Mapper disaster impact databases focusing on records from Australia. Whereas both databases emerge from similar definitions of disasters, substantial differences were found. A lack of some categories and general absence of definitions were noted when comparing them. An even more important aspect was the lack of a clearer data structure to report contextual and impact variables. Disaster Mapper considered war-related events not considered in EM-DAT, and considered the environmental impact of disasters and not just the direct human impacts.

Entry criteria for an event in the Disaster Mapper appears to align with the published criteria for the Australian Disasters Collection by including "natural, technological, and human-caused events that have a significant impact on Australia and its people." It is not clear how significance is calculated for international events, as other impacts on Australian Nationals abroad, such as the downing of Malaysia Airlines Flight 17 (MH17) on July 17, 2014 resulting in the death of 283 passengers, including 38 Australians, has not been included. Additionally, other historic natural disaster impacts, such as the volcanic eruption in Papua New Guinea (then a territory of Australia) that resulted in 4,000 deaths, are missing from the Disaster Mapper. ${ }^{20}$ It is unclear how or why events were selected for inclusion and others were not.

The EM-DAT database does not record war or conflictrelated events. Alternately, CRED has identified events related to the impact of war or conflict as "complex emergencies" from which the Complex Emergencies Events Database (CE-DAT) was developed and captures humanitarian emergency impact data. The intent of CE-DAT was monitoring and evaluation of the health status of populations affected by complex emergencies. The CE-DAT was initiated in 2003 to predominantly measure mortality and malnutrition from surveys conducted in humanitarian crises. The CE-DAT database is not currently operational.

The EM-DAT possesses a hierarchical clustering of main disaster categories and sub-categories, which could be used by Disaster Mapper to improve its classification structure and assist in addressing absence of categories for mass movement, meteorites, and volcanic activity.

Further comparisons of the datasets are challenging due to accessibility options. Whilst EM-DAT enables spreadsheet downloading of the data, Disaster Mapper data require manual extraction and configuration into usable tables. Overall, the differences in data collection and functionality between the two databases limit 
meaningful comparison. For data users, this can potentially challenge database utility for policy guidance, development, and decision making.

Consistent with the study results here, internationally led research has compared disaster loss databases in efforts to improve understanding of disaster impact. A report commissioned by the United Nations Development Program (UNDP; New York USA) reviewed country and regional disaster databases and highlighted that in the Asia Pacific region, of 19 different national databases that were identified, five (including Australia) had standalone methodologies for disaster event capture and recording. ${ }^{21}$ The remainder used DesInventar definitions and classifications. Disaster information captured by DesInventar format databases include: type of event, province/State, district, date, location, deaths, missing, injured, affected, victims, evacuated, relocated, houses damaged, houses destroyed, crops and woods (hectares), livestock (lost), educational centers, hospitals, loss value in local currency and USD (calculated according to the exchange rate on the date of the disaster), roads affected, and other data fields up to a maximum of 17 additional parameters (including data sources for each of the records). ${ }^{6}$ The Australian database examined by UNDP was reported as including event title, zone, region, category, start date, end date, dead, injured, and the insured total losses due to the disaster itself. Interestingly, the reference used by the report related to Australian disaster data is the Emergency Management Australia Disasters Database. ${ }^{22}$ The data set was created on May 2, 2014 and last updated on December 16, 2016 as a CSV format list of all Australian Emergency Management Knowledge Hub disaster events, including disaster category, impacts, and geographic coordinates. The dataset is publicly available for download but shows a difference in disaster events recorded (a total of 674) compared to Disaster Mapper.

Key findings noted by the UNDP report included opportunities for improvement in currency (up to date information), completeness (data gaps), quality assurance (having a documented quality control procedure), applications (use of the dataset for research or policy support), accessibility (having open access), and standardization (using consistent methodology). The report endorsed recommendations to improve disaster loss databases in respect to these criteria and defined the ideal loss and damage database as "one that is sustainable, continuous, credible, publicly accessible, quality assured, and applied for decision making." ${ }^{21}$ These recommendations are consistent with findings of an investigation into disaster data interoperability in Europe by Migliorini, et al who noted a lack of long-term DRR activities related to data capture and usage. ${ }^{23}$

The EM-DAT is one of very few global disaster event databases. The EM-DAT, along with other international databases, relies predominantly on media sources, international organizations (ie, UN, Red Cross), and/or non-governmental organization reports, resulting in a lack of readily available access to event data that national services possess. Consistent standards of data capture and shared access may enhance research capability to investigate disaster impact events. Findings from De Groeve, et al recommended guidelines and standards for data collection and recording, with a focus on human and economic losses, to enable data sharing in a comparable way. ${ }^{13}$

An investigation into decision making related to disaster resilience in Australia conducted by Deloitte found that gaps existed across categories of data and that "significant barriers exist to the better provision, sharing, and quality of natural disaster data sets."
Recommendations noted by Deloitte include a more coordinated approach to natural disaster data to reduce cost and support the quality of research activities and decision making related to resilience investments, and reduce the duplication of data collection and analysis. ${ }^{24}$

In a study using both CRED data and Knowledge Hub entry data, Bradt, et al sought to determine the profile of Australian Disaster since 1900. Large variations in data capture and classification were also identified by the author. To account for this and enable a sharper analysis, a methodology was developed by the author and applied using additional criteria in order to exclude events not deemed of national significance. ${ }^{25}$

The collection of accurate disaster loss information is of relevance to many stakeholders. Hallegatte, et al reported national and subnational levels of government, the insurance sector, the private sector, and the local and international community as having invested interest in disaster loss information to guide risk plans and actions. ${ }^{26}$

As described by De Groeve, et al, one of the main sources of incompatibilities between databases is the lack of precise and agreed definitions of hazards and loss indicators. ${ }^{13}$ The analysis here is coincident with the above statement. Enhancement of the Australian database could be achieved through adoption of the Integrated Research on Disaster Risk Programme hazard and peril classification, which is widely adopted across national and international databases. This classification distinguishes three levels: the event family (the most generic), the main event type, and peril (the most specific). ${ }^{17}$ These findings are consistent with the outcomes of a review of selected disaster databases by Tschoegl, et al who conducted a high-level overview of international and national disaster database methodologies. ${ }^{27}$

Australia is a signatory to the Sendai Framework for Disaster Risk Reduction, Priority 2, of which is "Strengthening disaster risk governance to manage disaster risk." 28 Differences in hazard definitions, lack of certain hazard categories, and varying entry criteria may result in inclusion of events in one dataset that may not be included in the other. This, in turn, can alter perception of, and decision making related to, risk and vulnerability to hazards or biased disaster response. Addressing this issue is of particular relevance as Australian disaster reporting seeks to move from a response to a prevention approach. ${ }^{18}$

There is no national strategy, organization, or capability to systematically capture, measure, and evaluate disaster event occurrence, impact, and outcomes and from this analyze and implement lessons and findings into policy or practice. The recently released report of the Royal Commission into National Natural Disaster Arrangements has recommended improvements in national practices of disaster data collection. In particular, implementation of harmonized data governance and national data standards and development of consistent data standards to measure disaster impact. ${ }^{29}$

The findings of this paper identify opportunities for improvement. This includes a recommendation of review of Australian disaster database hazard classification and definitions in alignment with the Integrated Research on Disaster Risk Programme hazard and peril classification. Further to this, standardization and systematic reporting of disaster data utilizing an agreed, fixed data structure including context and impact variables internationally is recommended. Finally, to enhance utility for generation of rapid situation reports or customized reports online, disaster database data extraction capability is recommended. 


\section{Limitations}

This study is not exempt from limitations, including the comparison of only two databases. Limited accessibility was observed at the time of the study. It should be noted that EM-DAT has enabled public access after this analysis was completed. This research was conducted from an Australian perspective and may lack validity outside of that perspective.

\section{Conclusion}

This paper provides a comparative analysis of disaster hazard and threat data of Australian events as measured by The Australian
Disaster Mapper and the CRED EM-DAT database. Differences in categorization and classification were identified, which may have implications for reporting and analysis. Further investigation to understand how significant events are identified for inclusion in disaster categories, and how their inclusion impact decision making for DRR activities in Australia, is warranted. Consistency in reporting methods based on international classification standards is recommended to improve the validity and usefulness of this Australian database.

\section{References}

1. Council of Australian Governments. National Strategy for Disaster Resilience. Building the Resilience of Our Nation to Disasters. Australian Capital Territory: COAG; 2011.

2. Coates L, Haynes K, O’Brien J, McAneney J, De Oliveira FD. Exploring 167 years of vulnerability: an examination of extreme heat events in Australia 1844-2010. Environmental Science E Policy. 2014;42:33-44.

3. Guha-Sapir D, Below R. The Quality and Accuracy of Disaster Data: A Comparative Analyses of 3 Global Data Sets. Centre for Research on the Epidemiology of Disasters (CRED) Working Paper. Brussels, Belgium: CRED; 2002.

4. Ladds M, Keating A, Handmer J, Magee L. How much do disasters cost? A comparison of disaster cost estimates in Australia. Int J Disaster Risk Reduction. 2017;21:419429.

5. Bureau of Transport Economics. Economic Cost of Natural Disasters in Australia. Report 103. Canberra, Australian Capital Territory: BOTE; 2001.

6. United Nations Office for Disaster Risk Reduction. DesInventar. UNISDR Disaster Information System. https://www.desinventar.net/. Accessed April 2, 2020.

7. Swiss Re. Sigma. Economic Research and Consulting. https://www.swissre.com/ institute/search-page.html?searchterm $=$ Economic + Research + and + Consulting. Accessed April 2, 2020.

8. Munich Re. Disaster loss data. NatCat Service. https://www.munichre.com/en/ solutions/for-industry-clients/natcatservice.html. Accessed April 2, 2020.

9. Disaster Assist. https://www.disasterassist.gov.au/Pages/australian-disasters.aspx. Accessed April 2, 2020.

10. Insurance Council of Australia (ICA). 2015, Historical disaster statistics. Sydney, Australia: Insurance Council of Australia. https://www.insurancecouncil.com.au/ industry-statistics-data/disaster-statistics/historical-disaster-statistics. Accessed April 2, 2020.

11. Handmer J, Ladds M, Magee L. Updating the costs of disasters in Australia. Austral J Emerg Manag. 2018;33(2):40.

12. Stratton SJ. Using pre-existing databases for prehospital and disaster research. Prehosp Disaster Med. 2015;30(1):1-3.

13. De Groeve T, Poljansek K, Ehrlich D, Corbane C. Current status and best practices for disaster loss data recording in EU member states: a comprehensive overview of current practice in the EU member states. JRC Scientific and Policy Report. JRC92290.

14. Australian Emergency Management. Australian Emergency Management Knowledge Hub. www.emknowledge.gov.au. Accessed April 2, 2020.
15. EM-DAT: The CRED/OFDA International Disaster Database. https://www. emdat.be/. Accessed April 2, 2020.

16. United Nations International Strategy for Disaster Reduction. UNISDR Terminology on Disaster Risk Reduction. Geneva, Switzerland: UNISDR; 2009.

17. IRDR DATA Working Group. Peril Classification and Hazard Glossary. DATA Project Report. Beijing, China: IRDR; 2014.

18. National Resilience Taskforce. The National Disaster Risk Reduction Framerwork. Canberra, Australian Capital Territory: Department of Home Affairs; 2018.

19. National Emergency Risk Assessment Guidelines. Australian Disaster Resilience Handbook Collection. Melbourne, Victoria, Australia: Australian Institute for Disaster Resilience; 2015.

20. Belshaw CS. Social consequences of the Mount Lamington eruption. Oceania. 1950;21:241.

21. Grasso V, Dilley M. A Comparative Review of Country-Level and Regional Disaster Loss and Damage Databases. New York USA: United Nations Development Programme Bureau for Crisis Prevention and Recovery; 2013.

22. Australian Government Data Portal. Disaster Events with Category Impact and Location. Attorney-General's Department; 2014. https://data.gov.au/data/dataset/ disaster-events-with-category-impact-and-location. Accessed January 8, 2020.

23. Migliorini M, Hagen JS, Mihaljević J, et al. Data interoperability for disaster risk reduction in Europe. Disaster Prevention and Management. 2019;28(6).

24. Deloitte Access Economics. Building An Open Platform for Natural Disaster Resilience Decisions. Sydney, New South Wales, Australia: Deloitte Access Economics; 2014.

25. Bradt DA, Bartley B, Hibble BA, Varshney K. Australasian disasters of national significance: an epidemiological analysis, 1900-2012. Emerg Med Australas. 2015;27(2):132-138.

26. Przyluski V, Hallegatte S. Indirect costs of natural hazards. CONHAZ Report WPO2. 2011;2:383-398.

27. Tschoeg1 L, Below R, Guha-Sapir D. An Analytical Review of Selected Data Sets on Natural Disasters and Impacts. Brussels, Belgium: Centre for Research on the Epidemiology of Disasters; 2006.

28. United Nations. Sendai Framework for Disaster Risk Reduction 2015-2030. Geneva, Switzerland: UNDRR; 2015.

29. Royal Commission into National Natural Disaster Arrangements. Report. Canberra, Australian Capital Territory: Commonwealth of Australia; 2020. 